\title{
Association of four gene polymorphisms in Chinese Guangxi population with diabetic retinopathy in type 2 diabetic patients
}

He $\mathrm{Jin}^{1{ }^{*}+}$, Dongdong Jiang ${ }^{1 \dagger}$, Zhixiang Ding ${ }^{1 \dagger}$, Yu Xiong ${ }^{2 \dagger}$, Xinsheng Zeng ${ }^{1}$, Miaoyun Liao ${ }^{1}$, Liu Zheng ${ }^{1}$ and Binbin Yang ${ }^{1}$

\begin{abstract}
s
Background: Diabetic retinopathy (DR) is one of the most common chronic microvascular complications of diabetes. Many studies have suggested that genetic factors are important in the context of DR. This study evaluated the associations of GWAS (Genome-wide association study) -identified DR-associated SNPs in a Chinese population in Guangxi Province with type 2 diabetes mellitus (T2DM).
\end{abstract}

Methods: A total of 386 hospitalized T2DM patients without proliferative diabetic retinopathy (PDR) and 316 hospitalized T2DM patients with PDR were included in this case-control study. Four tag SNPs, including rs 1800896 in the IL-10 gene, rs2010963 in the VEGFA gene, rs2070600 in the RAGE gene and rs2910164 in the miR-146a gene, were examined using KASP (kompetitive allele specific PCR) genotyping assays.

Results: There were no significant differences in the genotype or allele frequencies of the miR-146a polymorphism (rs2910164) between subjects with PDR and those without DR. The TC genotype of rs1800896 was determined to be associated with an increased risk of PDR (the odds ratio (OR) was 2.366, with a 95\% confidence interval (Cl) ranging from 1.144 to 4.894). The CG genotypes of rs 2010963 was associated with an decreased risk of PDR (the OR was 0.588, with a 95\% Cl ranging from 0.366 to 0.946). Regarding rs2070600, 2 genotypes (TT and CT) were associated with a decreased risk of PDR (the OR of the TT genotype was 0.180 , with a $95 \% \mathrm{Cl}$ ranging from 0.037 to 0.872 , and the OR of the CT genotype was 0.448 , with a $95 \% \mathrm{Cl}$ ranging from 0.266 to 0.753 ).

Conclusions: The rs 1800896 polymorphisms in the IL-10 gene, rs2010963 in the VEGFA gene and rs2070600 in the RAGE gene are associated with the risk of PDR in the Han Chinese population of Guangxi Province. Our findings provide suggestive evidence that these polymorphisms may be involved in the pathogenesis of PDR and should be investigated further.

Keywords: Diabetic retinopathy, Single nucleotide polymorphisms, Type 2 diabetes mellitus, KASP genotyping assays

*Correspondence: jinhe930930@glmc.edu.cn

${ }^{\dagger} \mathrm{He}$ Jin, Dongdong Jiang, Zhixiang Ding and Yu Xiong contributed equally to this paper.

1 Affiliated Hospital of Guilin Medical University, Guilin Medical University, Guilin 541001, China

Full list of author information is available at the end of the article

\section{Introduction}

Diabetes is an endocrine disease that severely impacts human health, and its disability and fatality rates are second only to those of cardiovascular and cerebrovascular diseases and cancer [1]. It is estimated that the percentage of people with diabetes worldwide will reach $4.4 \%$ by 2030 [2]. It has been recognized that diabetes is a main source of morbidity and mortality given its related acute 
and chronic side effects. Diabetic retinopathy (DR) is one of the most common chronic microvascular side effects of diabetes [3]. With the incidence of diabetes increasing worldwide, the incidence of DR is expected to increase to alarming levels [4]. Furthermore, DR is the main cause of blindness in diabetic patients [3].

Diabetes duration, poor glycaemic control and hypertension are known as the primary risk factors related to the progression of DR [4]. However, clinical observation has revealed that some patients with poorly controlled or long-lasting diabetes do not develop retinopathy, whereas others, even those with relatively good glycaemic control, eventually develop advanced retinopathy [5]. These clinical observations suggest that other factors are involved in the development of DR. Many studies suggest that genetic factors are important in the context of DR, that DR exhibits a complicated inheritance mode and that genetic relationship studies are useful for the identification of the genetic elements impacting the pathogenesis of DR [6]. According to this information, genetic elements exert an effect on the development of DR [7]. It has been estimated that the heritability of DR is approximately $25 \%$ [8]. Through an increased understanding of the genetic foundation of DR, the hidden pathophysiological mechanisms governing its development can be identified. These genetic data may also be useful for the risk profiling of DR among patients suffering from diabetes, thereby promoting its early treatment and administration. Robust relationships of DR-susceptibility variants may make them ideal genetic markers to enhance the prediction of DR via traditional clinical predictors and thus achieve more precise risk stratification.

Genome-wide association studies (GWASs) represent a selective strategy for the detection of new genetic loci related to DR, and some GWASs have been performed using different ethnic groups to identify novel genetic variants related to DR susceptibility in diabetes mellitus cohorts [9-12]. Single nucleotide polymorphisms (SNPs) are deoxyribonucleic acid (DNA) sequences that commonly differ in populations [13]. These changes in DNA sequences may affect gene expression if they occur in putative regulatory regions [13]. In several previous reports, some GWAS-identified SNPs were found to be highly associated with DR $[6,14-16]$.

In our previous study, we analysed the association of 20 SNPs selected from 11 DR-associated factors, which were reported in previous reports [6, 14, 16-24]. These 11 DRassociated factors were Interleukin-10 (IL-10), Vascular endothelial growth factor (VEGF), Receptor for advanced glycation end product (RAGE), microRNA-146a (miR146a), Intercellular adhesion molecule-1 (ICAM-1), complement factor $\mathrm{H}(\mathrm{CFH})$, Transforming growth factor- $\beta 1$ (TGF- $\beta 1)$, Endothelin 1 (EDN1), Osteoprotegerin (OPG),
C-reactive protein (CRP), Tumor necrosis factor- $\alpha$ (TNF$\alpha)$. The causal relationship between inflammation and angiogenesis in PDR is widely accepted [25]. And in the Petrovič's study [26], they summarized the IL-10, VEGF and RAGE were the candidate genes for proliferative diabetic retinopathy (PDR). The miR-146a was also associated with microvascular complications [16]. And those four DR-associated factors were across varying diseases in different ethnicities $[16,18]$. According to the previous reports $[6,16,27,28]$, we selected 4 SNPs of those 4 factors, which were identified in the GWAS. And whether these four DR-associated SNPs influence PDR in the Han Chinese population of Guangxi Province has not been examined in a systematic way. Therefore, this study primarily aims to assess the relationships of GWAS-recognized DR-related SNPs in this population with type 2 diabetes mellitus (T2DM).

\section{Materials and approaches \\ Research population}

The research protocol was examined by the Research Ethics Committee of the Affiliated Hospital of Guilin Medical University and adhered to the principles of the Declaration of Helsinki. All participants gave written informed consent before their enrolment. A total of 386 T2DM patients without diabetic retinopathy (DR) and 316 T2DM patients with proliferative diabetic retinopathy (PDR) were included in this case-control study. All patients' data were collected from the endocrinology department and ophthalmology department and were included in the study in the enrolment. All patients lived in Guangxi Province and were Han Chinese. The diagnosis of type 2 diabetes was made on the basis of the American Diabetes Association criteria [29]. All patients received ophthalmic examinations such as best-modified visual acuity, intraocular pressure, slit lamp, and dilated fundus examinations, in the Department of Ophthalmology, Affiliated Hospital of Guilin Medical University. PDR was defined as having eyes with definite neovascularization and/or vitreous/preretinal haemorrhages. Patient and medical data, including age, sex, age at diabetes diagnosis, presence of arterial hypertension, application of medication or insulin, and other comorbidities, were collected using a questionnaire. Individuals with peripheral vascular diseases, coronary artery diseases, acute infection, history of any thrombotic event, or any other ocular disorders were excluded.

\section{Genotyping}

Whole-blood specimens from all patients were gathered in EDTA tubes and stored at $-20^{\circ} \mathrm{C}$ for less than 2 months. A TIANamp Genomic DNA Kit (TianGen, Beijing, China) was used to extract genomic DNA from 
whole blood before analysis. Genotyping for SNP screening analyses was conducted using the KASP (kompetitive allele specific PCR) assay. Equal amounts of genomic DNA $(0.8 \mu \mathrm{l} /$ patient) from DR and DNR patients were mixed with the KASP Master Mix and KASP Assay Mix. Next, the SNP-containing DNA fragments were amplified by PCR. The PCR program was as follows: initial denaturation at $94^{\circ} \mathrm{C}$ for $15 \mathrm{~min}, 10$ cycles of denaturation at $94^{\circ} \mathrm{C}$ for $20 \mathrm{~s}$ and annealing at $65^{\circ} \mathrm{C}\left(0.8^{\circ} \mathrm{C}\right.$ decrease every cycle) for $1 \mathrm{~min}$; and 27 cycles of a final extension at $59^{\circ} \mathrm{C}$ for $1 \mathrm{~min}$. Primers for the KASP SNP assays were designed using Primer Premier 5.0, and allele frequencies were analysed using IntelliQube software (LGC Genomics, UK).

\section{Statistical analyses}

Continuous data are shown as the mean \pm SD. Categorical variables are reported as numbers (percentages) or percentages. The normality of the distribution of quantitative variables was verified by the Kolmogorov-Smirnov test. After the normal distribution test, the comparison of continuous variables among groups of diabetic subjects was made by ANOVA for normally distributed variables. The $\chi^{2}$ test was used to compare categorical variables. Gene counting was applied to determine allele frequencies, and the $\chi^{2}$ test was used to verify departures from Hardy-Weinberg equilibrium. The comparison between allele and genotype frequencies was made among groups of subjects using the $X^{2}$ test. SPSS (version 20.0; SPSS, Inc., Chicago, IL, USA) was employed to conduct statistical analyses. We considered $P$ values less than 0.2 to be great for inclusion in multivariate analysis. Multivariate analysis, adjusting for the use of insulin treatment, systolic blood pressure and glomerular filtration rate (GFR), was performed with binary logistic regression analysis. According to the outcomes, odds ratios and $95 \%$ confidence intervals (CIs) are shown. We considered $P$ values less than 0.05 to be statistically significant.

\section{Results}

\section{Clinical data of the research population}

Table 1 summarizes the features of the subjects. The cases and controls were 58.5 and 58.95 years of age on average, respectively, and the groups included 44.04 and $44.87 \%$ females, respectively, indicating good match between two groups with regard to age and sex (both $P>0.05$ ). No significant variation was noted in the duration of DM, body mass index, HbA1c, HDL cholesterol, total cholesterol or LDL cholesterol between the groups. There were significant differences in analyzing systolic blood pressure and using insulin treatment and glomerular filtration rate (GFR) between the groups.

\section{Candidate gene and single nucleotide polymorphism selection}

We selected 4 SNPs (rs1800896, rs2010963, rs2070600, rs2910164), which from IL-10, VEGF, RAGE and miR146a, respectively. And these genes were related to DR in at least one population or are logical candidate genes according to the present understanding of the pathogenesis of DR; there are selected SNPs in the promoter areas, $5^{\prime}$ UTR regions, or coding areas of candidate genes. In addition, the total call rates of these 4 SNPs (rs1800896, rs2010963, rs2070600, and rs2910164) were $99.43,98.86,97.72$, and $84.90 \%$, respectively.

Table 1 Comparison of clinical features between two groups

\begin{tabular}{|c|c|c|c|}
\hline Clinical characteristics (Variable) & NDR group ( $n=386)$ & PDR group $(n=316)$ & $P$-value \\
\hline Female $[\mathrm{n}(\%)]$ & $170(44.04)$ & $140(44.87)$ & 0.877 \\
\hline Age [years, mean $\pm S D$ ] & $58.50 \pm 11.44$ & $58.95 \pm 10.16$ & 0.699 \\
\hline Duration of DM [years, mean \pm SD] & $9.53 \pm 7.07$ & $10.10 \pm 7.24$ & 0.472 \\
\hline Body mass index (BMI) $\left[\mathrm{kg} / \mathrm{m}^{2}\right.$, mean $\left.\pm \mathrm{SD}\right]$ & $23.922 \pm 3.127$ & $24.701 \pm 4.760$ & 0.093 \\
\hline $\mathrm{HbA} 1 \mathrm{c}[\%(\mathrm{mmol} / \mathrm{mol})$, mean $\pm \mathrm{SD}]$ & $8.668 \pm 2.432$ & $8.677 \pm 2.520$ & 0.976 \\
\hline Insulin treatment [n (\%)] & $180(46.63)$ & $212(67.52)$ & 0.001 \\
\hline Hypertension [n (\%)] & $168(43.52)$ & $142(45.22)$ & 0.750 \\
\hline Systolic blood pressure [mmHg, mean \pm SD] & $130.65 \pm 17.41$ & $135.05 \pm 18.06$ & 0.025 \\
\hline Diastolic blood pressure $[\mathrm{mmHg}$, mean $\pm \mathrm{SD}]$ & $81.01 \pm 9.56$ & $80.17 \pm 10.40$ & 0.437 \\
\hline Total cholesterol [mM, mean \pm SD] & $4.290 \pm 1.188$ & $4.448 \pm 1.258$ & 0.259 \\
\hline HDL cholesterol [mM, mean \pm SD] & $1.028 \pm 0.273$ & $1.080 \pm 0.360$ & 0.155 \\
\hline LDL cholesterol $[\mathrm{mM}$, mean \pm SD] & $2.711 \pm 0.967$ & $2.853 \pm 0.908$ & 0.190 \\
\hline Glomerular filtration rate (GFR) $[\mathrm{ml} / \mathrm{min}$, mean $\pm \mathrm{SD}]$ & $84.970 \pm 33.218$ & $75.951 \pm 28.971$ & 0.013 \\
\hline
\end{tabular}


Polymorphisms of 4 SNPs in type 2 diabetic subjects based on the presence of PDR

The distribution of the genotype and allele frequencies of the 4 SNPs' polymorphisms in type 2 diabetic subjects based on the presence of PDR are shown in Table 2. All 4 SNPs were distributed in accordance with Hardy-Weinberg equilibrium. No significant variation in the genotype and allele frequencies of the miR-146a polymorphism (rs2910164) was noted between subjects with PDR and those without DR, indicating that this SNP might not be related to the presence of PDR. However, the data show that the other 3 SNP (rs1800896, rs2010963 and rs2070600) were significantly associated with the presence of PDR.

Multivariable logistic regression analysis showed that 3 SNPs (rs1800896, rs2010963 and rs2070600) were associated with the PDR phenotype after adjustment for insulin therapy, systolic blood pressure and GFR. The frequency of the TC genotype of rs1800896 was higher among subjects with PDR than in those without DR (16.03\% vs. $8.29 \%, P=0.002)$. The frequency of the TT genotype was lower in subjects with PDR $(82.69 \%$ vs. $91.71 \%, P=0.001)$. After multivariable analysis, the TC genotype was determined to be related to an increased risk of PDR. The odds ratio (OR) was 2.366 , with a $95 \%$ confidence interval $(\mathrm{CI})$ ranging from 1.144 to 4.894 ( $P$ adjusted $=0.020$ ). The frequency of the CG genotype of rs2010963 was reduced in subjects with PDR compared with those without DR ( $44.87 \%$ vs. $56.02 \%, P=0.003)$. After multivariable analysis, the $\mathrm{CG}$ genotypes were related to a decreased risk of PDR. The OR of the CG genotype was 0.588 , with a $95 \% \mathrm{CI}$ ranging from 0.366 to 0.946 ( $P$ adjusted $=0.028$ ). The frequency of the CC genotype of rs2070600 was increased among subjects with PDR than in those without DR (66.67\% vs. $51.81 \%$, $P=0.001)$. The frequency of the CT genotype was lower in subjects with PDR (30.67\% vs. $41.97 \%, P=0.002)$. Multivariable analysis revealed that the other 2 genotypes (TT and CT) were related to a reduced risk of PDR. The OR of the TT genotype was 0.180 , with a $95 \% \mathrm{CI}$ ranging from 0.037 to $0.872\left(P_{\text {adjusted }}=0.033\right)$. The OR of the CT genotype was 0.448 , with a $95 \% \mathrm{CI}$ ranging from 0.266 to $0.753\left(P_{\text {adjusted }}=0.002\right)$.

\section{Discussion}

Many studies have suggested that genetic factors are important in the context of DR. In this study, we analyzed the association of 4 SNPs selected from 4 DR-associated factors in an independent cohort of patients in Guangxi Province with type 2 diabetes mellitus (T2DM). Our data showed significant associations with the IL-10, VEGF and RAGE genes.

It has been proposed that DR is associated with persistent low-grade inflammation [30]. Interleukin-10 (IL-10) prevents the generation of proinflammatory cytokines and stimulates the proliferation, differentiation

Table 2 Analysis of 4 SNPs in NDR and PDR groups

\begin{tabular}{|c|c|c|c|c|c|c|c|c|c|c|}
\hline \multirow[t]{2}{*}{ Gene } & \multirow[t]{2}{*}{ SNP } & \multirow[t]{2}{*}{ Allele } & \multirow[t]{2}{*}{ NDR [\%] } & \multirow[t]{2}{*}{ PDR [\%] } & \multirow[t]{2}{*}{ Geno-type } & \multirow[t]{2}{*}{ NDR [n (\%)] } & \multirow[t]{2}{*}{ PDR [n (\%)] } & \multirow{2}{*}{$\begin{array}{l}\mathrm{X}^{2} \text { test } \\
P \text {-value }\end{array}$} & \multicolumn{2}{|c|}{ Logistic regression analysis } \\
\hline & & & & & & & & & $\begin{array}{l}\text { odds ratio } \\
(95 \% \mathrm{CI})\end{array}$ & $P_{\text {adjust }}$-value \\
\hline \multirow[t]{4}{*}{ IL-10 } & rs1800896 & $\mathrm{T}$ & 95.85 & 90.71 & $\mathrm{TC}$ & $32(8.29)$ & $50(16.03)$ & 0.002 & $2.366(1.144,4.894)$ & 0.020 \\
\hline & & C & 4.15 & 9.29 & $\mathrm{CC}$ & $0(0)$ & $4(1.28)$ & 0.026 & $1.524(0)$ & 0.999 \\
\hline & & & & & $\mathrm{TT}$ & $354(91.71)$ & $258(82.69)$ & 0.001 & Reference & \\
\hline & & & & & Total & 386 & 312 & & & \\
\hline \multirow[t]{4}{*}{ VEGFA } & rs2010963 & C & 39.00 & 34.62 & CG & $214(56.02)$ & $140(44.87)$ & 0.003 & $0.588(0.366,0.946)$ & 0.028 \\
\hline & & G & 60.99 & 65.38 & CC & $42(10.99)$ & $38(12.18)$ & 0.627 & $1.277(0.578,2.821)$ & 0.546 \\
\hline & & & & & GG & $126(32.98)$ & $134(42.95)$ & 0.007 & Reference & \\
\hline & & & & & Total & 382 & 312 & & & \\
\hline \multirow[t]{4}{*}{ RAGE } & rs2070600 & C & 72.80 & 82.00 & $\mathrm{CC}$ & $200(51.81)$ & $200(66.67)$ & 0.001 & Reference & \\
\hline & & $\mathrm{T}$ & 27.20 & 18.00 & $\mathrm{TT}$ & $24(6.22)$ & $8(2.67)$ & 0.029 & $0.180(0.037,0.872)$ & 0.033 \\
\hline & & & & & $\mathrm{CT}$ & $162(41.97)$ & $92(30.67)$ & 0.002 & $0.448(0.266,0.753)$ & 0.002 \\
\hline & & & & & Total & 386 & 300 & & & \\
\hline \multirow[t]{4}{*}{ miR-146a } & rs2910164 & C & 63.68 & 65.88 & $\mathrm{CC}$ & $158(41.58)$ & $132(44.59)$ & 0.432 & - & \\
\hline & & G & 36.32 & 34.12 & $\mathrm{GG}$ & $54(14.21)$ & $38(12.84)$ & 0.606 & - & \\
\hline & & & & & CG & $168(44.21)$ & $126(42.57)$ & 0.669 & - & \\
\hline & & & & & Total & 380 & 296 & & & \\
\hline
\end{tabular}

Bold indicates statistically significant results

$P_{\text {adjust }}$ values were adjusted for systolic blood pressure and using insulin treatment and glomerular filtration rate (GFR) 
and survival of several types of immune cells [31]. Most cells of the adaptive and innate immune systems such as dendritic cells, leukocytes, and macrophages express IL-10 [31]. DR progression may be promoted by IL-10, an anti-inflammatory cytokine with strong deactivating nature [14]. IL-10 gene rs1800896 polymorphism (IL-10 -1082G/A polymorphism) in the promoter region was associated with production of IL-10 [32]. And it is reported that the IL-10 gene polymorphism is related to the risk of DR among various populations [14, 33, $34]$. This study showed that the TC genotype was associated with the risk for PDR. The various genetic backgrounds of the study samples, sample sizes, exposure to environmental factors, and clinical phenotypes of PDR may explain the conflicting outcomes reported by the abovementioned studies. According to the multivariable analyses, the IL-10 rs1800896 polymorphism is associated with a significant risk of PDR. However, these outcomes should be explained carefully due to the limited sample sizes in the stratified analyses and the limited power. However, evidence for a possible effect between the rs 1800896 polymorphism and several T2DM risk elements is indicated by our findings.

Vascular endothelial growth factor (VEGF) drives angiogenesis, breaks down the blood-retinal barrier, excites the growth of endothelial cells, induces neovascularization, and enhances vascular permeability in the ischaemic retina [35, 36]. Increased expression level of VEGF has been observed in DR patients [37]. In Yang's study [38], they summarized that the rs2010963 was a risk contributor to PDR in overall populations, while no significant association was detected between rs2010963 and PDR risk in Caucasians. Our analysis demonstrated that carriers of the CG genotype had a lower risk for PDR compared with those with the GG genotype. In accordance with our study, Awata and coworkers [39] found no association between the CC genotype of rs2010963 polymorphism and PDR. Carriers of another 2 additional homozygous genotypes exhibited altered susceptibility to DR, suggesting that rs2010963 might be an important genetic marker for DR among patients in Guangxi Province with T2DM. Many factors could determine the differences in the findings, such as sample size, study design, and sunlight exposure [40].

Receptor for advanced glycation end product (RAGE) gene polymorphisms impact DR due to pathophysiological information related to retinopathy and advanced glycation end products (AGEs) [6]. The RAGE gene is located on the short arm of chromosome 6: 6p21.3 [17]. AGEs result from the nonenzymatic glycation of proteins and lipids [41]. AGEs are observed at enhanced levels in individuals with diabetes and can result in enhanced oxidative stress and receptor-mediated activation and secretion of different cytokines [41]. The RAGE polymorphism assessed in this study occurs at a predicted $\mathrm{N}$-linked glycosylation motif in the AGE binding site, impacting AGE-RAGE interactions [6]. This study analysed the RAGE SNP (rs2070600), and the results showed that TT genotype or $\mathrm{T}$ allele carriers were associated with a reduced risk for PDR. Similar strong relationships between rs2070600 and diabetic retinopathy were also observed in Asian Indians and Asian Chinese people with type 2 diabetes and in an Indian study $[6,17]$. Moreover, analysis of the allelic frequency of rs 2070600 in different ethnic groups showed different results. The $\mathrm{T}$ allele frequency in this research was $18.00 \%$ in the PDR group, which is similar to the findings of an earlier report in the Chinese population (23.1\%) [42] and another report in the Japanese population (17.3\%) [43]. In previous reports, the $\mathrm{T}$ allele occurred with an incidence of $5 \%$ in Caucasians [44] and 2\% in Indians [45]. Allelic variants of the RAGE gene may alter protein function and gene expression, which may influence disease progression. The high proportion of variant alleles in the Chinese population may confer enhanced susceptibility to diabetic side effects in this population.

In Kaidonis' study [16], rs2910164 was found to potentially enhance susceptibility to retinal injury via a pathway involved in both angiogenesis and breakdown of the blood retinal barrier. This SNP significantly related to $\mathrm{DN}$ in patients suffering from type 1 diabetes mellitus (T1DM) after multivariate analysis [16]. In our study, we collected samples from T2DM patients to analyse the risk of DR, but T1DM and T2DM are unique diseases with various aetiologies. DR progression is impacted by environmental elements that may occur under the background of a given type of diabetes mellitus. Furthermore, DR commonly develops early in susceptible patients with T1DM [46]. Statistical analysis revealed that rs2910164 was not significantly related to DR. Further studies with a larger cohort size are warranted to more accurately assess these given phenotypes in relation to microRNA-146a (miR-146a) SNPs.

Potential limitations of the current study should be taken into account. First, the sample size was not large, which may have caused our study to be underpowered. Second, we cannot exclude confounding effects of unmeasured variables that may affect the stability of blood glucose levels, such as dietary and other lifestyle factors. Third, no detailed information regarding DR severity or treatment response was obtained, which limited our conclusions. Fourth, we planned to avoid population substructures in our research. Nevertheless, it is possible that the positive and negative outcomes obtained in this study may be attributed to subtle population stratification, and the results should be considered suggestive 
instead of definitive. Moreover, our study requires a more direct assessment of the association between SNPs and related serum levels. The mechanisms underlying these SNPs in DR merit further study.

\section{Conclusion}

According to the outcomes of this research, the rs1800896 polymorphisms in the IL-10 gene, rs2010963 in the VEGFA gene and rs2070600 in the RAGE gene are related to the risk of PDR in the Han Chinese population of Guangxi Province. Our findings provide suggestive evidence that these polymorphisms may be involved in the pathogenesis of PDR and should be examined further. Moreover, our study suggests that the rs2910164 polymorphism in the miR-146a gene may not be related to DR in the Guangxi Province population. Nevertheless, these findings should be examined by additional welldesigned multicentre studies with larger sample sizes that include gene-environment interaction assessments.

\begin{abstract}
Abbreviations
DR: Diabetic retinopathy; PDR: Proliferative diabetic retinopathy; T2DM: Type 2 diabetes mellitus; T1DM: Type 1 diabetes mellitus; KASP: Kompetitive allele specific PCR; DNA: Deoxyribonucleic acid; GWAS: Genome-wide association study; GFR: Glomerular filtration rate; IL-10: Lnterleukin-10; VEGF: Vascular endothelial growth factor; RAGE: Receptor for advanced glycation end product.
\end{abstract}

\section{Acknowledgements}

The authors are grateful for the help provided by the Guilin Medical University Affiliated Hospital. And Thanks American Journal Experts (AJE) supporting Premium Editing Service for this manuscript.

\section{Authors' contributions}

All authors made substantial contributions to conception and design. Dongdong Jiang, Liu Zheng, Yu Xiong and Binbin Yang collected the data. Zhixiang Ding, Xinsheng Zeng and Miaoyun Liao made substantial contributions to analysis and interpretation of data. He Jin and Dongdong Jiang wrote the first draft of the manuscript. All authors were involved in revising the manuscript critically for important intellectual content. And He Jin has given final approval of the version to be published. All authors read and approved final manuscript.

\section{Funding}

Funding support is provided by the Technology Base and talent special project of Guangxi Province (AD19110131) and the Natural Science Foundation of Guangxi Province for Youth (2018GXNSFBA050055).

\section{Availability of data and materials}

The datasets of primer used during the current study are available online (https://pan.baidu.com/s/1V45I_EnSPxPzrV768sGw6w, code: f06e) or from the corresponding author on reasonable request.

\section{Declarations}

\section{Ethics approval and consent to participate}

No animals were used in this research. The study adhered to the tenets of the Declaration of Helsinki. Written informed consent was obtained from all participants prior to their enrolment. All experiments were approved by the Ethics Committee of Affiliated Hospital of Guilin Medical University (Acceptance number: GLMU1A2019120).
Consent for publication

Not applicable.

\section{Competing interests}

All the authors declare that they have no competing interests.

\section{Author details}

${ }^{1}$ Affiliated Hospital of Guilin Medical University, Guilin Medical University, Guilin 541001, China. ${ }^{2}$ Nanxishan Hospital of Guangxi Zhuang Autonomous Region, Guilin Medical University, Guilin 541001, China.

Received: 31 May 2021 Accepted: 18 October 2021

Published online: 27 October 2021

\section{References}

1. Solomon SD, Chew E, Duh EJ, Sobrin L, Sun JK, VanderBeek BL, et al. Diabetic retinopathy: a position statement by the American Diabetes Association. Diabetes Care. 2017:40(3):412-8.

2. Shaw JE, Sicree RA, Zimmet PZ. Global estimates of the prevalence of diabetes for 2010 and 2030. Diabetes Res Clin Pract. 2010;87(1):4-14.

3. Zheng Y, He M, Congdon N. The worldwide epidemic of diabetic retinopathy. Indian J Ophthalmol. 2012;60(5):428-31.

4. Zorena K, Raczyńska D, Raczyńska K. Biomarkers in diabetic retinopathy and the therapeutic implications. Mediat Inflamm. 2013;2013:193604.

5. Sobrin L, Green T, Sim X, Jensen RA, Tai ES, Tay WT, et al. Candidate gene association study for diabetic retinopathy in persons with type 2 diabetes: the candidate gene association resource (CARe). Invest Ophthalmol Vis Sci. 2011;52(10):7593-602.

6. Balasubbu S, Sundaresan P, Rajendran A, Ramasamy K, Govindarajan G, Perumalsamy N, et al. Association analysis of nine candidate gene polymorphisms in Indian patients with type 2 diabetic retinopathy. BMC Med Genet. 2010;11:158.

7. Cheung CY, Hui EY, Lee CH, Kwok KH, Gangwani RA, Li KK, et al. Impact of genetic loci identified in genome-wide association studies on diabetic retinopathy in Chinese patients with type 2 Diabetes. Invest Ophthalmol Vis Sci. 2016;57(13):5518-24.

8. Kuo JZ, Wong TY, Rotter Jl. Challenges in elucidating the genetics of diabetic retinopathy. JAMA Ophthalmol. 2014;132(1):96-107.

9. Grassi MA, Tikhomirov A, Ramalingam S, Below JE, Cox NJ, Nicolae DL. Genome-wide meta-analysis for severe diabetic retinopathy. Hum Mol Genet. 2011;20(12):2472-81.

10. Huang YC, Lin JM, Lin HJ, Chen CC, Chen SY, Tsai CH, et al. Genome-wide association study of diabetic retinopathy in a Taiwanese population. Ophthalmology. 2011;118(4):642-8.

11. Graham PS, Kaidonis G, Abhary S, Gillies MC, Daniell M, Essex RW, et al. Genome-wide association studies for diabetic macular edema and proliferative diabetic retinopathy. BMC Med Genet. 2018;19(1):71.

12. Liu C, Chen G, Bentley AR, Doumatey A, Zhou J, Adeyemo A, et al. Genome-wide association study for proliferative diabetic retinopathy in Africans. NPJ Genom Med. 2019;4:20.

13. Wang X, Tomso DJ, Liu X, Bell DA. Single nucleotide polymorphism in transcriptional regulatory regions and expression of environmentally responsive genes. Toxicol Appl Pharmacol. 2005;207(2 Suppl):84-90.

14. Liu L, Zheng J, Xu Y, Gao J, Fan L, Xu D. Association between interleukin-10 gene rs 1800896 polymorphism and diabetic retinopathy in a Chinese Han population. Biosci Rep. 2019;39(4):BSR20181382.

15. Chen CF, Liou SW, Wu HH, Lin CH, Huang LS, Woung LC, et al. Regulatory SNPs Alter the gene expression of diabetic retinopathy associated secretary factors. Int J Med Sci. 2016;13(9):717-23.

16. Kaidonis G, Gillies MC, Abhary S, Liu E, Essex RW, Chang JH, et al. A singlenucleotide polymorphism in the MicroRNA-146a gene is associated with diabetic nephropathy and sight-threatening diabetic retinopathy in Caucasian patients. Acta Diabetol. 2016;53(4):643-50.

17. Serveaux-Dancer M, Jabaudon M, Creveaux I, Belville C, Blondonnet R, Gross C, et al. Pathological implications of receptor for advanced glycation end-product (AGER) gene polymorphism. Dis Markers. 2019;2019:2067353.

18. Simoes MJ, Lobo C, Egas C, Nunes S, Carmona S, Costa MA, et al. Genetic variants in ICAM1, PPARGC1A and MTHFR are potentially associated 
with different phenotypes of diabetic retinopathy. Ophthalmologica. 2014;232(3):156-62.

19. Wang J, Yang MM, Li YB, Liu GD, Teng Y, Liu XM. Association of CFH and CFB gene polymorphisms with retinopathy in type 2 diabetic patients. Mediat Inflamm. 2013;2013:748435.

20. Liu L, Jiao J, Wang Y, Wu J, Huang D, Teng W, et al. TGF-beta1 gene polymorphism in association with diabetic retinopathy susceptibility: a systematic review and meta-analysis. PLoS One. 2014;9(4):e94160.

21. Li H, Louey JW, Choy KW, Liu DT, Chan WM, Chan YM, et al. EDN1 Lys198Asn is associated with diabetic retinopathy in type 2 diabetes. Mol Vis. 2008;14:1698-704.

22. Mankoc Ramus S, Kumse T, Globocnik Petrovic M, Petrovic D, Cilensek I. SNP rs2073618 of the osteoprotegerin gene is associated with diabetic retinopathy in Slovenian patients with type 2 diabetes. Biomed Res Int. 2013;2013:364073.

23. Peng $\mathrm{D}$, Wang J, Zhang $\mathrm{R}$, Tang $\mathrm{S}$, Jiang $\mathrm{F}$, Chen $\mathrm{M}$, et al. C-reactive protein genetic variant is associated with diabetic retinopathy in Chinese patients with type 2 diabetes. BMC Endocr Disord. 2015;15:8.

24. Sesti LF, Crispim D, Canani LH, Polina ER, Rheinheimer J, Carvalho PS, et al. The -308G $>$ a polymorphism of the TNF gene is associated with proliferative diabetic retinopathy in Caucasian Brazilians with type 2 diabetes. Invest Ophthalmol Vis Sci. 2015;56(2):1 184-90.

25. van Beijnum JR, Buurman WA, Griffioen AW. Convergence and amplification of toll-like receptor (TLR) and receptor for advanced glycation end products (RAGE) signaling pathways via high mobility group B1 (HMGB1). Angiogenesis. 2008;11(1):91-9.

26. Petrovic D. Candidate genes for proliferative diabetic retinopathy. Biomed Res Int. 2013;2013:540416.

27. Shi YL, Shi MY, Yin LZ, Shang JM, Zhuang JY. IL-10 gene polymorphism in diabetic retinopathy. Eur Rev Med Pharmacol Sci. 2019;23(12):5059-64.

28. Awata T, Kurihara S, Takata N, Neda T, lizuka H, Ohkubo T, Osaki M, Watanabe M, Nakashima Y, Inukai K et al: Functional VEGF C-634G polymorphism is associated with development of diabetic macular edema and correlated with macular retinal thickness in type 2 diabetes. Biochem Biophys Res Commun 2005, 333(3):679-685.

29. American Diabetes A. Diagnosis and classification of diabetes mellitus. Diabetes Care. 2014;37(Suppl 1):S81-90.

30. Tang J, Kern TS. Inflammation in diabetic retinopathy. Prog Retin Eye Res. 2011;30(5):343-58.

31. Saxena A, Khosraviani S, Noel S, Mohan D, Donner T, Hamad AR. Interleukin-10 paradox: a potent immunoregulatory cytokine that has been difficult to harness for immunotherapy. Cytokine. 2015;74(1):27-34.

32. Lin MT, Storer B, Martin PJ, Tseng LH, Gooley T, Chen PJ, et al. Relation of an interleukin-10 promoter polymorphism to graft-versus-host disease and survival after hematopoietic-cell transplantation. N Engl J Med. 2003;349(23):2201-10.

33. Rodrigues KF, Pietrani NT, Sandrim VC, Vieira CM, Fernandes AP, Bosco AA, et al. Association of a Large Panel of cytokine gene polymorphisms with complications and comorbidities in type 2 Diabetes patients. J Diabetes Res. 2015;2015:605965.
34. da Silva Pereira BL, Polina ER, Crispim D, Sbruzzi RC, Canani LH, Dos Santos KG. Interleukin-10 -1082A>G (rs1800896) polymorphism is associated with diabetic retinopathy in type 2 diabetes. Diabetes Res Clin Pract. 2018;138:187-92.

35. Tarr JM, Kaul K, Chopra M, Kohner EM, Chibber R. Pathophysiology of diabetic retinopathy. ISRN Ophthalmol. 2013;2013:343560.

36. Zhang XL, Wen L, Chen YJ, Zhu Y. Vascular endothelial growth factor upregulates the expression of intracellular adhesion molecule-1 in retinal endothelial cells via reactive oxygen species, but not nitric oxide. Chin Med J. 2009;122(3):338-43.

37. Jain A, Saxena S, Khanna VK, Shukla RK, Meyer CH. Status of serum VEGF and ICAM-1 and its association with external limiting membrane and inner segment-outer segment junction disruption in type 2 diabetes mellitus. Mol Vis. 2013;19:1760-8.

38. Yang $Q$, Zhang Y, Zhang X, Li X, Liu J. Association of VEGF gene polymorphisms with susceptibility to diabetic retinopathy: a systematic review and Meta-analysis. Horm Metab Res. 2020;52(5):264-79.

39. Awata T, Inoue K, Kurihara S, Ohkubo T, Watanabe M, Inukai K, et al. A common polymorphism in the $5^{\prime}$-untranslated region of the VEGF gene is associated with diabetic retinopathy in type 2 diabetes. Diabetes. 2002;51(5):1635-9.

40. Wang H, Cheng JW, Zhu LS, Wei RL, Cai JP, Li Y, et al. Meta-analysis of association between the -2578C/a polymorphism of the vascular endothelial growth factor and retinopathy in type 2 diabetes in Asians and Caucasians. Ophthalmic Res. 2014;52(1):1-8.

41. Brownlee M, Cerami A, Vlassara H. Advanced glycosylation end products in tissue and the biochemical basis of diabetic complications. N Engl J Med. 1988;318(20):1315-21.

42. Liu L, Xiang K. RAGE Gly82Ser polymorphism in diabetic microangiopathy. Diabetes Care. 1999;22(4):646.

43. Yoshioka K, Yoshida T, Takakura Y, Umekawa T, Kogure A, Toda H, et al. Relation between polymorphisms G1704T and G82S of rage gene and diabetic retinopathy in Japanese type 2 diabetic patients. Intern Med. 2005;44(5):417-21.

44. Hudson BI, Stickland MH, Grant PJ. Identification of polymorphisms in the receptor for advanced glycation end products (RAGE) gene: prevalence in type 2 diabetes and ethnic groups. Diabetes. 1998;47(7):1155-7.

45. Kumaramanickavel G, Ramprasad VL, Sripriya S, Upadyay NK, Paul PG, Sharma T. Association of Gly82Ser polymorphism in the RAGE gene with diabetic retinopathy in type II diabetic Asian Indian patients. J Diabetes Complicat. 2002;16(6):391-4.

46. Ng SM, Ayoola OO, McGuigan MP, Chandrasekaran S. A multicentre study evaluating the risk and prevalence of diabetic retinopathy in children and young people with type 1 diabetes mellitus. Diabetes Metab Syndr. 2019;13(1):744-6.

\section{Publisher's Note}

Springer Nature remains neutral with regard to jurisdictional claims in published maps and institutional affiliations.

\footnotetext{
Ready to submit your research? Choose BMC and benefit from:

- fast, convenient online submission

- thorough peer review by experienced researchers in your field

- rapid publication on acceptance

- support for research data, including large and complex data types

- gold Open Access which fosters wider collaboration and increased citations

- maximum visibility for your research: over $100 \mathrm{M}$ website views per year
}

At BMC, research is always in progress.

Learn more biomedcentral.com/submissions 